\title{
Effectiveness of ontological security training on psychological safety and existential anxiety of elder people
}

*Yarian $\mathrm{S}^{1}$, Rahian $\mathrm{H}^{2}$, Asgharnejad Farid AA ${ }^{3}$, Vahedi $\mathrm{H}^{4}$, Ameri $\mathrm{NF}^{5}$, Dehghan Najmabadi

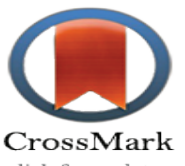

$\mathrm{M}^{6}$

CrossMark

1- MSc, Department of Clinical Psychology, Iran University of Medical Sciences, Tehran, Iran (Corresponding Author)

E-mail: sajadyaryan@gmail.com

2. MA, Department of Psychology, Allameh Tabataba'i University, Tehran, Iran.

3- Associate Professor, Department of Clinical Psychology, Iran University of Medical Sciences, Tehran, Iran.

4- PhD, Department of Psychology, Islamic Azad University, Central Tehran Branch, Tehran, Iran.

5- MA, Department of Psychology, Islamic Azad University, Central Tehran Branch, Tehran, Iran.

6- PhD, Department of Humanistic Sciences, Islamic Azad University, Central Tehran Branch, Tehran, Iran.

\section{Abstract}

Introduction: Old ages are one of the most major period of human life which because of its nature and being close to death time enhances deep questions about existential identity of man, anxiety related to effacement and annihilation, meaningfulness, feelings of unsafety, loneliness and seclusion in mind of most elder people. So this research has been done to review the effectiveness of ontological security training on psychological safety and existential anxiety of elder people in nursing home of Yasuj city.

Method: This study is a semi-experimental, two-group test with pretest, posttest and two-month follow up. The population includes all elder people residing at Ferdows nursing home in Yasuj city in 2018. The statistical sample is a 30-people group which was purposively selected and randomly divided into two test and control groups (each of 15 people). The test group was trained by 6 weekly meetings each takes 45 minutes with the training program of ontological security based on Giddens theory, while the control group had no interfere during the research. Then people of both groups have been post-tested and followed up. The data gathering tools were psychological safety questionnaire (Edmondson, 1999) and existential anxiety questionnaire (Weems et al, 2004) and the data was analyzed by repeated measure ANOVA in SPSS, v 23.

Results: : The results showed that ontological security training significantly affects psychological safety $(\mathrm{P}<0.001)$ and existential anxiety $(\mathrm{P}<0.05)$ of elder people in nursing home, but this significance was not prolonged for existential anxiety in follow up step $(\mathrm{P}>0.05)$. Hence this kind of training could result in increasing psychological safety and decreasing existential anxiety of elder people of the center.

Conclusion: Ontological security training decrease some part of existential anxiety of elder people while improving their psychological safety, so it could be applied as an effective training method for elder people.

Keywords: Ontological security, Psychological safety, Existential anxiety, Elder people.

Received: 25 April 2019

Accepted: 29 May 2019

\begin{tabular}{|l|l|}
\hline \multicolumn{3}{|c|}{ Access this article online } \\
\hline
\end{tabular}




\section{اثربخشى آموزش امنيت هستىشناختى بر امنيت روانى و اضطراب وجودى سالمندان}

\section{"*سجاد ياريان'، هادى رهيان"، علىاصغر اصغرنزاد فريد"، هليا واحدى"، نازنينفاطمه عامرى ه. مهناز دهقان نجهآبادى"}

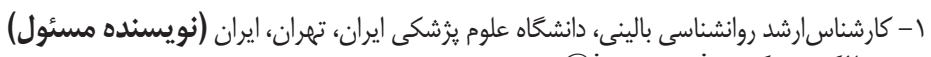
يست الكترونيكى: yaryan.s@iums.ac.ir

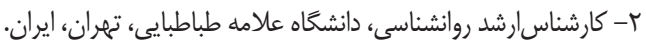

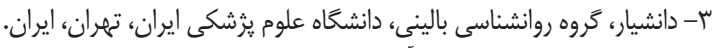

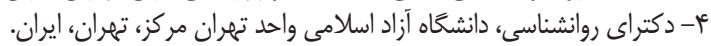

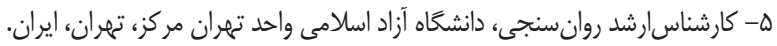
9- دكتراى زبانشاسى، دانشخاه آزاد اسلامى واحد تهران مركز، تهران، ايران.

\section{جكيده}

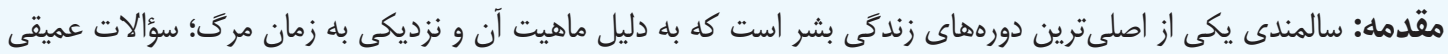

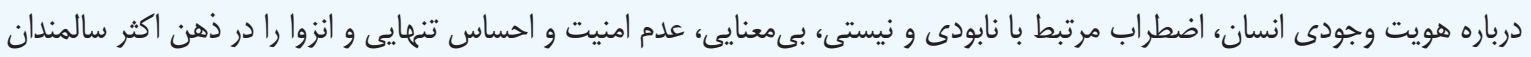

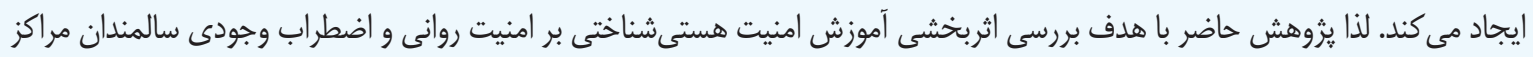
نكَّهارى شهر ياسوج انجام كَرديد.

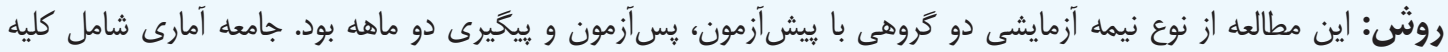

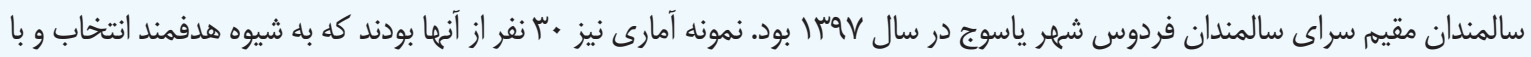

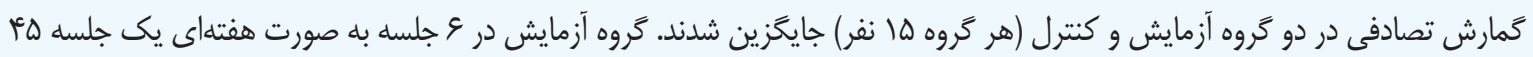

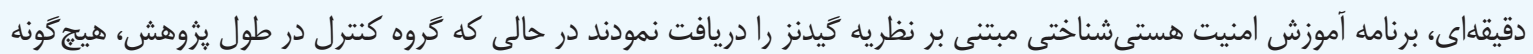

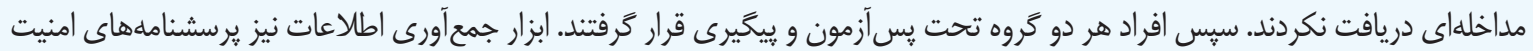

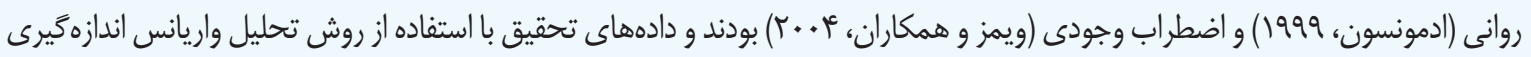

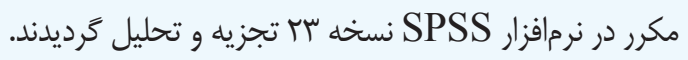

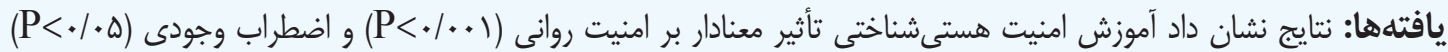

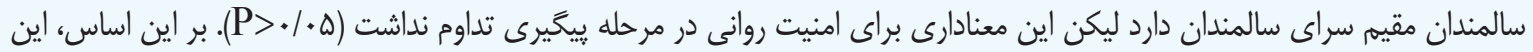

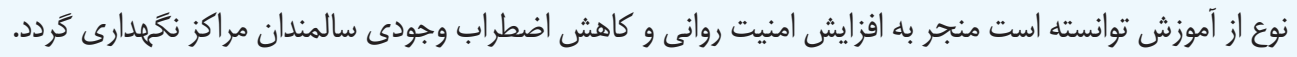

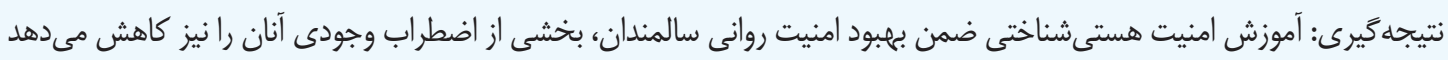

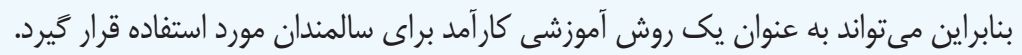

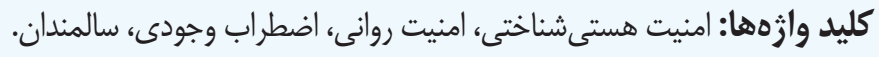


تهديداتى است كه به فرد امكان و اجازه مىدهد تا اميد و شهامت خود را برابر هر نوع شرايط مخرب و تضعيفكننداي كه شايد در

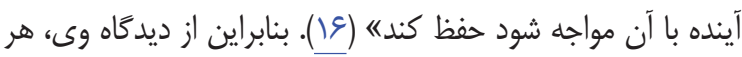

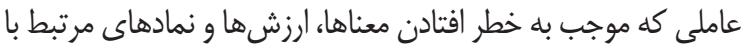
آنان در نزد آدمى گَردد، موجب نوعى احساس نامنى هستى شناختى

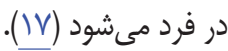

در اين ميان، يكى از متغيرهاى مرتبط با هستى و وجود كه

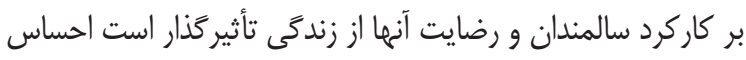

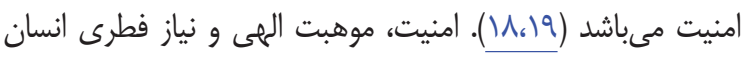

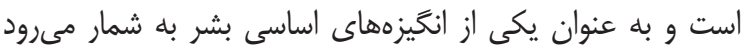

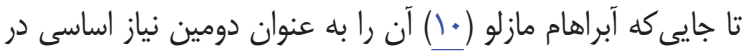

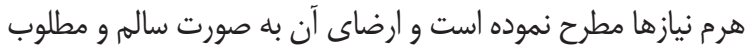

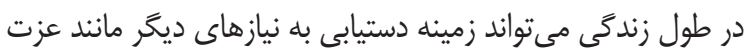
نفس، دوستداشتن و دوست داشتهشدن و خودشكوفايى را فراهم

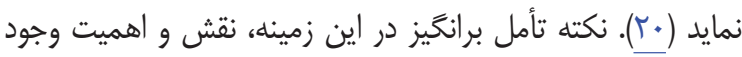
احساس امنيت است؛ يعنى در كنار وجود امنيت در بعد عينى، بايد از

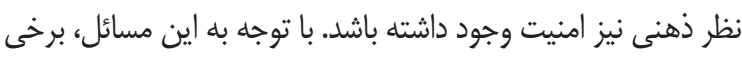
از كارشناسان احساس امنيت را مقدم بر وجود عينى امنيت مىدانند

امنيت روانى كه مىتوان آن را امنيت ذهنى يا احساس امنيت درونى نيز دانست هموارترين بستر رويش خلاقيتها و نوآورىهاى ذهنى است. احساس امنيت روانى از بارزترين ويثگى هاى شخصيتى ندانى افراد خلاق و تواناست و مؤثرترين شيوه ترغيب افراد به تفكر و تلاش جهت دستيابى به رشد و ييشرفت در سطوح مختلف فردى،

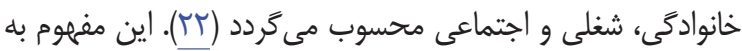
محيطى اشاره دارد كه به عنوان "يك فضاى غير شخصى و غير محتى

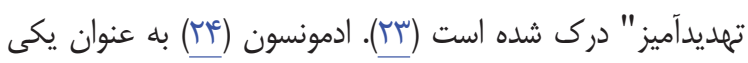

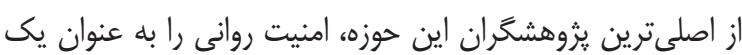
باور مشترك تعريف كرده است مبنى بر اينكه فضاى مرتبط با كروه براى ريسكيذيرى بينفردى امن است. بر اين اساس، تحقيقات نشان دادهاند زمانى كه امنيت روانى برقرار باشد افراد به احتمال

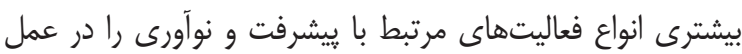
نشان مىدهند و ديدكاه بهترى درباره آينده خويش دارند كه در بران سالمندان نيز نمود زيادى دارد (צى،ه؟، -1). همجنين علاوه بر امنيت روانى و اهميت آن در سالمندى، آندان يكى از دغدغهها و نخرانىهاى اصلى سالمندان، اضطراب وجودى است كه بيانكر اضطراب بنيادين ناشى از درك بودن (حضور در دنيا)

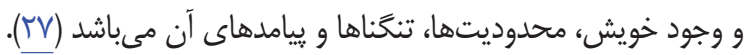

مقامه

يكى از مسائل مهم قرن حاضر، يديده يِيرى (سالمندى) است و جمعيت جهان به سرعت به سمت سالخورده شدن بيش بيش مىرود ((). بر اساس سرشمارى سال هوسبا، جمعيت سالمند ايران

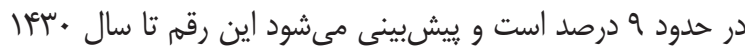

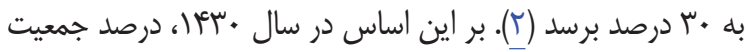

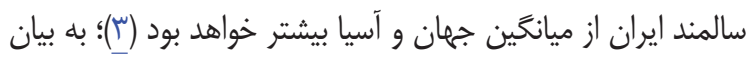
ديكر، هرم سنى كشور تا سال • بَع| استوانهاى مىشود و به تعبيرى، "سونامى سالمندى" در راه است (عا).). در اين ميان، آنجه مشخص

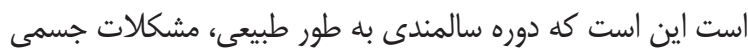

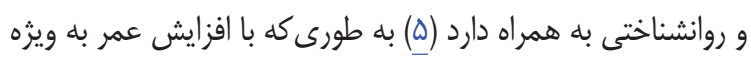
هِ از •و سالحَى، اغلب كاركردهاى فيزيولوزيكى و مكانيكى بدن

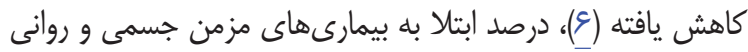

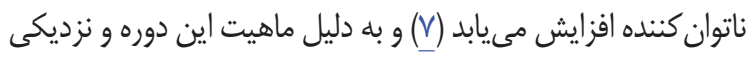
به زمان مرك، سؤالات عميقى درباره هويت وجودى انسان، اضطراب مرتبط با نابودى و نيستى، بىمعنايى، عدم امنيت، احساس تنهايى و واني

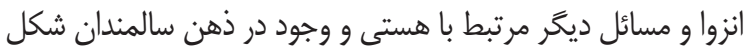

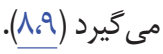

هستى شناسى يا وجودَرايى يكى از جنبشهاى فلسفى اجتماعى دوران معاصر است كه به عنوان واكنشى به رويكردهاى مصرفكرايى، مادى توجه به دغدغههاى اصيل انسان مطرح شد (•) (1). اين رويكرد در حوزه روانشناسى به عنوان وضعيتى مشترك براى همه افراد بدون توجه به مذهب، فرهنگ، قوميت و نزاد؛ به بررسى مسائل محورى

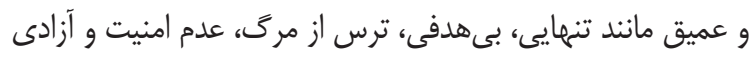

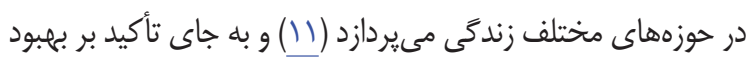
بيمارى يا بهكارگيرى مطلق تكنيكهاى حل مسأله براى تكليف

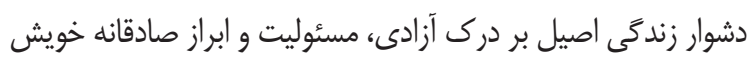

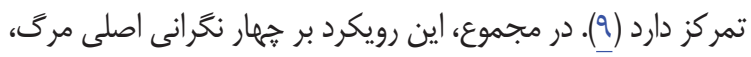
آزادى در عين حفظ امنيت، تنهايى و بىمعنايى كه در وجود انسان

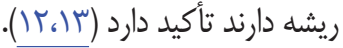

مفهوم هستىشناسى و امنيت مرتبط با آن نيز يكى از

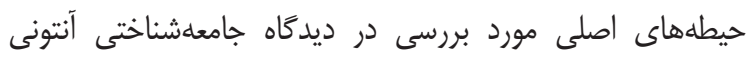

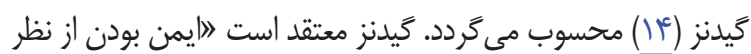
هستى شناختى يعنى در اختيار داشتن קاسخهايى در سطح ناخودآكاه و خودآكاه براى بعضى برسشهاى وجنى دودى بنيادين كه همه آدميان

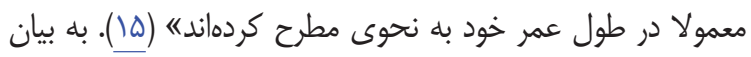

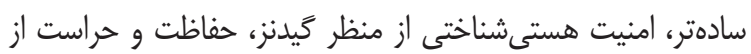


مرگ داشته باشد.

بنابراين با توجه به اينكه با نزديك شدن بله دوره سالمندى،

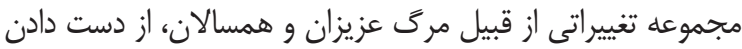
قدرت، اهداف زندگَى، مهارتهاى جسمانى و موقعيت اجتماعى به فيه وقوع مىييوندد كه امنيت روانى و اضطراب وجودى فرد سالمند را تحت الشعاع قرار مىدهد و از سوى ديگر، افراد سالمند درصد وله

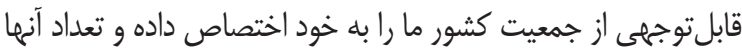

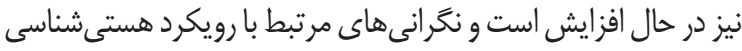
مانند هويت وجودى انسان، اضطراب مرتبط با نابودى و نيستى، بـىمعنايى، عدم امنيت و احساس تنهايى و انزوا نيز در اين گَروه سنى

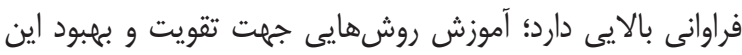

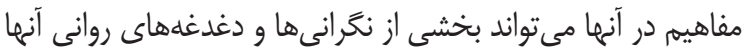

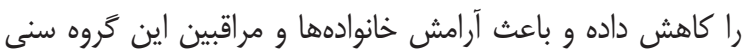

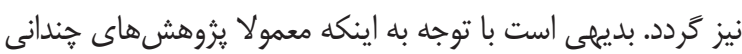
نيز متأسفانه به دليل مشكلات كار با سالمندان در اين حوزه انجام نمى امنيت هستى شناختى (مبتنى بر نظريه گَيدنز) بر امنيت روانى و اضطراب وجودى سالمندان لازم و ضرورى بوده است.

\section{و ش}

اين مطالعه از نوع كارآزمايى بالينى و طرح نيمهآزمايشى دو

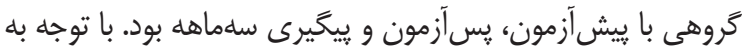

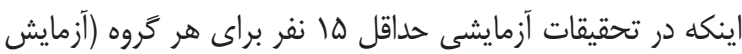

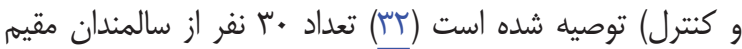
سراى سالمندان شهر ياسوج به شيوه نمونه كَيرى هدفمند انتخاب و

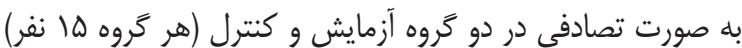

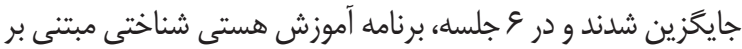

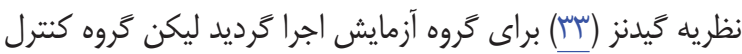

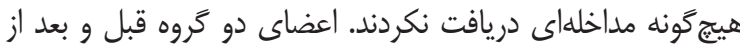

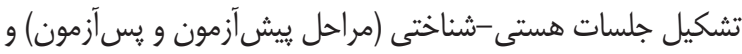

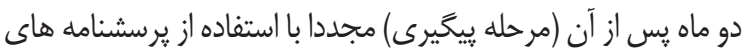
زير مورد ارزيابى قرار گرفتند.

يرسشنامه امنيت روانشناختى: يرسشنامه امنيت روانشناختى

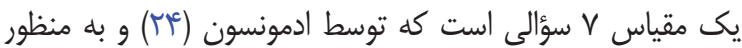

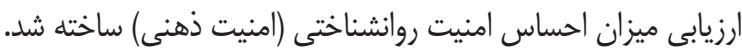

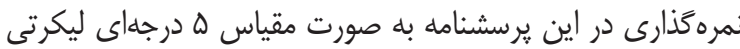

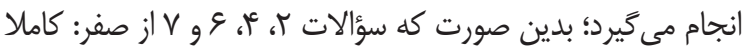
مخالفم تا ع: كاملا موافقم و سؤالات ا، ساو ه از از صفر: كاملا موافقهم

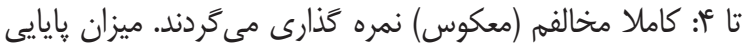

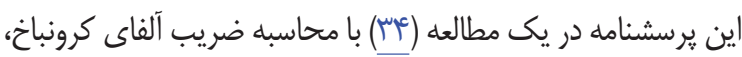

اضطراب وجودى نوعى تشويش بنيادى يا بىقرارى است كه آدميان

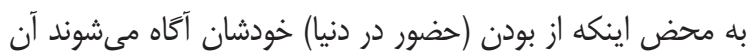
را تجربه مى كنند. در واقع اضطراب وجودى احساسى است كه با با بهون

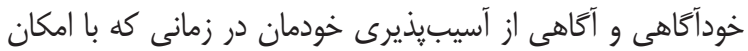

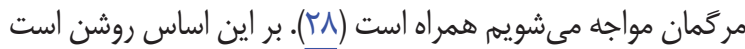

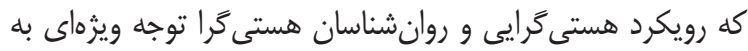
دوران ييبرى دارند زيرا يكى از مراحل مهمر رشد است كه احتمالا بيش رونس

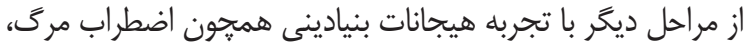

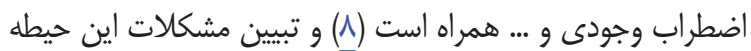
بر اساس نظريdهاى جامعه شناختى مانند نظريه گيدنز (أl). با توجه

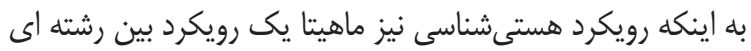

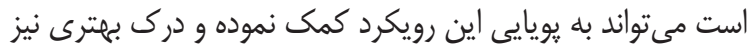
از مشكلات مرتبط با هستى و وجود فراهم نمايد.

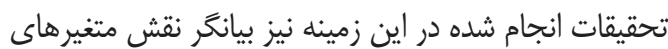
هستىشناختى در احساس امنيت، اعتماد بينفردى، كاهش ترس از

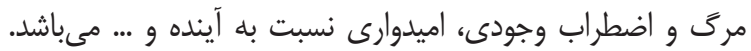
براى مثال حاجى عزيزى، بهمنى، مهدى، منظرى توكلى و برشان

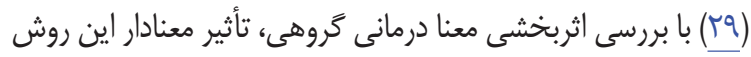
درمانى بر اضطراب مرگ و اميد به زندگى سالمندان مقيم مراكز

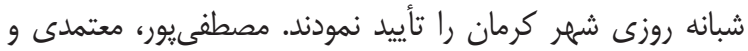

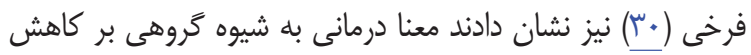

احساس تنهايى و اضطراب مرگ زنان سالمند تأثير معنادار دارد. در يزوهشهاى خارجى نيز شيور و ميكولينسر (.1) با مطالعه

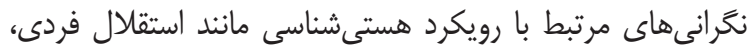

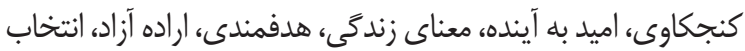

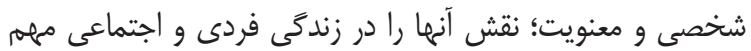

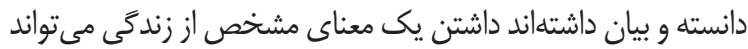

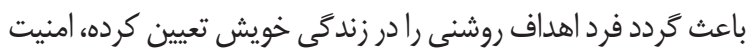
روانى داشته باشند و با آرامش بيشترى خود را براى زندگى يس از مرك

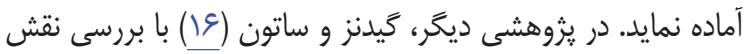

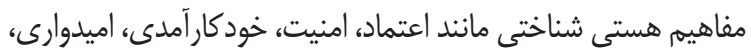
مسئوليتيذيرى اجتماعى، همدلى و هدفمندى در هويتيابى، ترس مانس

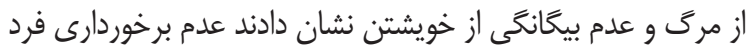

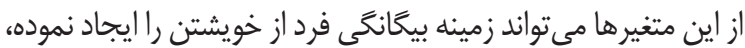
امنيت روانى و اجتماعى را مختل و فرد را جهت مقابله با مشكلات

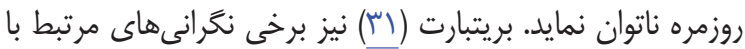

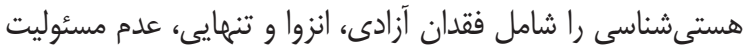

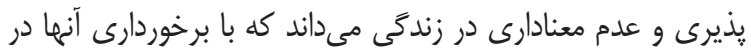

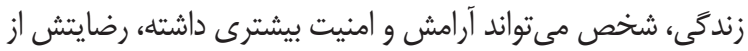

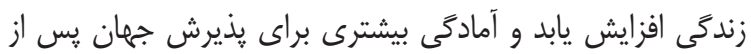


ويزّيهاى روانسنجى مقياس اضطراب وجودى در سالمندان ايرانى

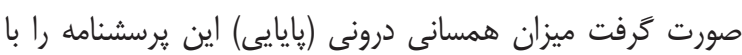
محاسبه ضريب آلفاى كرونباخ براى خرده مقياس هائ داى مركى

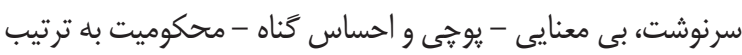

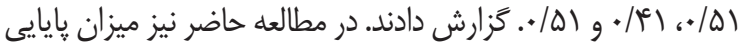
ير سشنامه اضطراب وجودى براى كل يرسشنامه و سه خرده مقياس مرك - سرنوشت، بى معنايى - يوجى و احساس كَناه - محكوميت

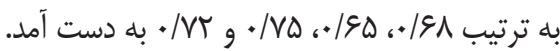
شيوه اجرا

جهت اجراى جلسات آموزشى، بعد از توجيه اهداف يزوهش آنش

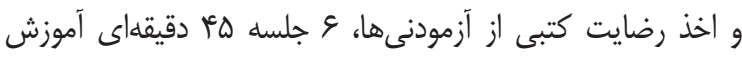
امنيت هستى شناختى (هر هفته يك جلسه) براى كروه آزمايش اجرا

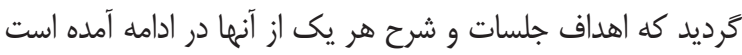

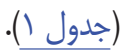

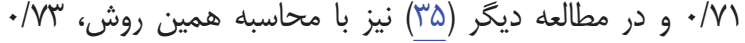

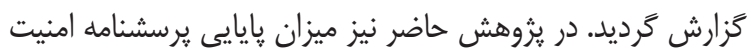

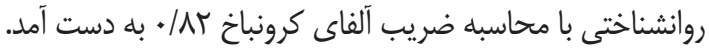
يرسشنامه اضطراب وجودى: اين يرسشنامه كه توسط ويمز،

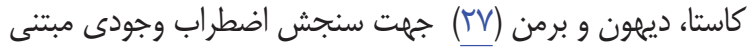

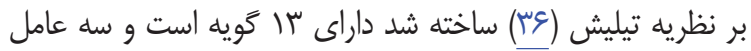

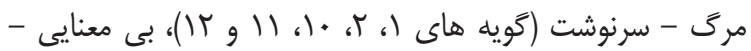

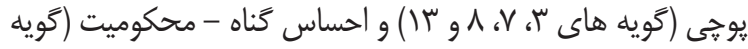

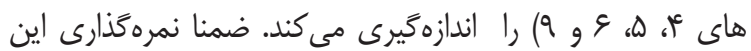
يرسشنامه به صورت ه درجهاى ليكرتى از صفر: اصلا تا أ: خيلى أنى

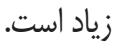
ويمز و همكاران (TV) ميزان پايايى اين يرسشنامه را با روش

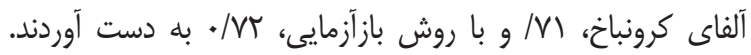

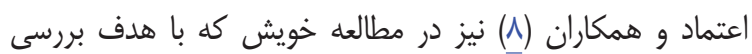

جدول ا : اهداف و محتواى جلسات آموزش هستىشناسى (بّ)

\begin{tabular}{|c|c|c|}
\hline شرح جلسه & هدف جلسه & جلسه \\
\hline 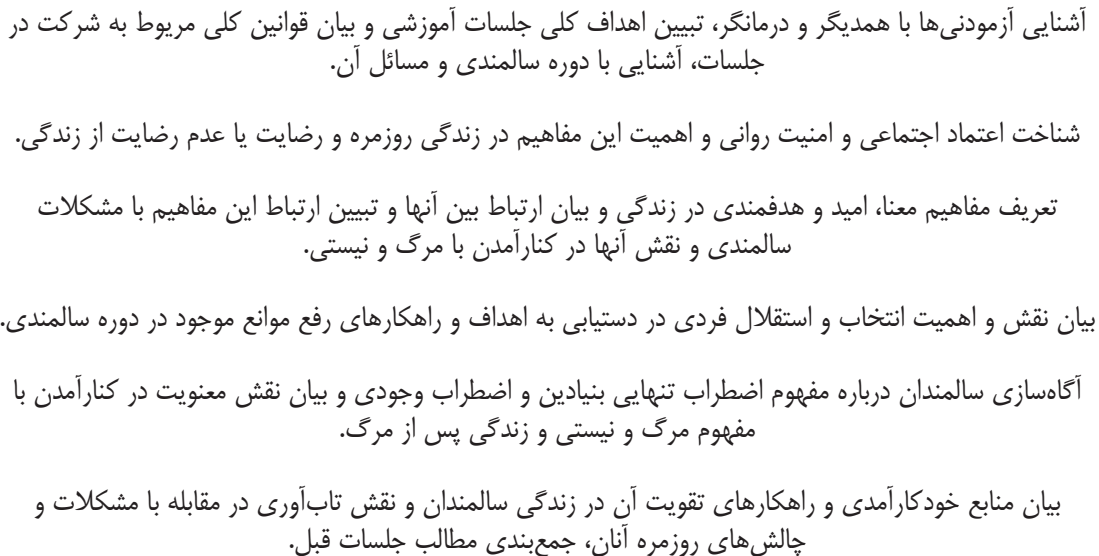 & 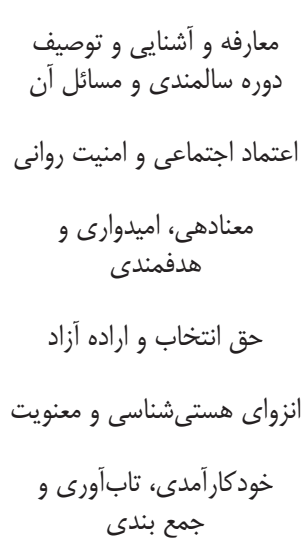 & 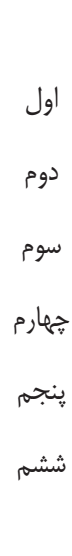 \\
\hline
\end{tabular}

ضمنا دادههاى تحقيق حاضر جهت تحليل وارد نرمافزار در اين قسمت يافتههاى توصيفى مربوط به ميانگين و نسخه سץ شدند و با توجه به بررسى تغييرات متغيرهاى انحراف معيار متغيرهاى وابسته (امنيت روانى و اضطراب وجودى)

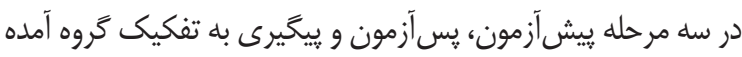

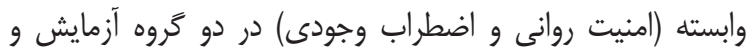
كنترل و سه مرحله يِش آزمون، يِ آزمون و يبيخيرى از آزمون تحليل

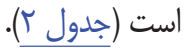

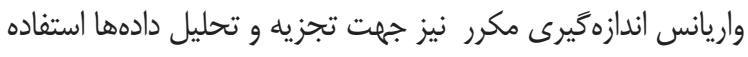

جدول ץ: ميانگين و انحر اف معيار امنيت روانى و اضطراب وجودى سه مرحله ييشآزمون، يس آزمون و ييخيرى به تفكيك گروه

\begin{tabular}{|c|c|c|c|c|}
\hline يِيخيرى & يِيش آزمون & يِيش آزمون & \multirow{2}{*}{ 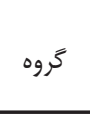 } & \multirow{2}{*}{ متغير } \\
\hline انحراف معيار 土 ميانگين & انحراف معيار 土 ميانخين & انحراف معيار 土 ميانگين & & \\
\hline 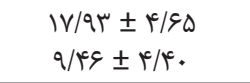 & $\begin{array}{l}1 \phi / V \Psi \pm r / v \varepsilon \\
q / \Lambda \varepsilon \pm r / v \varepsilon\end{array}$ & $\begin{array}{l}8 / \Lambda \cdot \pm 1 / 99 \\
\Delta / \& \& \pm 1 / 90\end{array}$ & كنترل & امنيت روانى \\
\hline $\begin{array}{l}q / \Lambda \varepsilon \pm r / \Delta f \\
r \cdot / \Lambda \varepsilon \pm V / \cdot r\end{array}$ & $\begin{array}{l}W / \Lambda \cdot \pm r / \Delta r \\
r / / \cdot \pm \pm \Delta / \cdot r\end{array}$ & 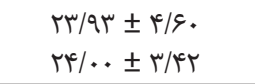 & كنترل & اضطراب وجودى \\
\hline
\end{tabular}


(آزمون لوين) به عنوان دو ييشفرض آزمون تحليل واريانس اندازه

كيرى مكرر بيانكر رعايت اين دو ييشفرض بود (جدول ب).
در ابتدا بايد كَفت بررسى ييشفرضهاى نرمالبودن توزيع

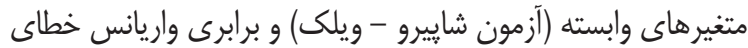
متغيرهاى وابسته (امنيت روانى و اضطراب وجودى) در دو كروه جدول ب: نتايج آزمونهاى شايبيرو-ويلك و لوين متغيرهاى وابسته (امنيت روانى و اضطراب وجودى)

\begin{tabular}{|c|c|c|c|c|c|c|c|c|c|c|c|c|}
\hline \multicolumn{4}{|c|}{ يبيغيرى } & \multicolumn{4}{|c|}{ ييش آزمون } & \multicolumn{4}{|c|}{ ييش آزمون } & \multirow{3}{*}{ متغير } \\
\hline \multicolumn{2}{|c|}{ لوين } & \multicolumn{2}{|c|}{ شاييرو - ويلك } & \multicolumn{2}{|c|}{ لوين } & \multicolumn{2}{|c|}{ شاييرو - ويلك } & \multicolumn{2}{|c|}{ لوين } & \multicolumn{2}{|c|}{ شاييرو - ويلك } & \\
\hline Sig & $\mathrm{F}$ & Sig & $\mathrm{F}$ & Sig & $\mathrm{F}$ & Sig & $\mathrm{F}$ & Sig & $\mathrm{F}$ & Sig & $\mathrm{F}$ & \\
\hline$\cdot / r \Lambda$ & $1 / 1$ & $\cdot / \cdot 1$ &.$/ 94$ & $\cdot / \Delta S$ & 政 & $\cdot / \mathrm{V}$ & $\cdot / 90$ & r T & $\cdot / \pi r$ & .1 .9 &.$/ 91$ & امنيت روانى \\
\hline .199 & .199 & .1 .9 & .95 & . $/ \Lambda t$ & $r / \Lambda 1$ & tet &.$/ 9 \mathrm{~V}$ & . & .191 &.$/ . v$ & س (q) & اضطراب مرى \\
\hline
\end{tabular}

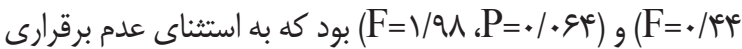
شرط كرويت (آزمون مايلى) براى اضطراب وجودى، بيانكر رعايت

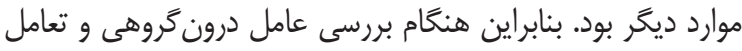
عامل درونَّروهى و بينَروهى تحليل واريانس اندازمَيرى مكرر (جدوله) از شاخص گرينهاوس-كيزر براى اضطراب وجودى لئى

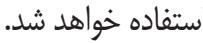

همجنين بررسى نتايج دو ييشفرض ديخر تحليل واريانس

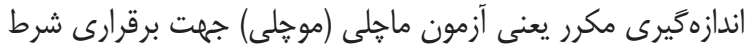

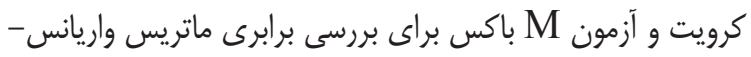

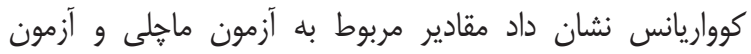

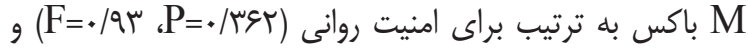

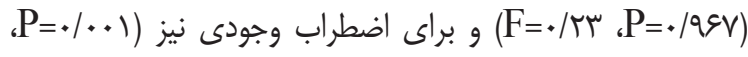

جدول عا: نتايج تحليل واريانس اندازهيرى مكرر متغيرهاى وابسته براى اثرات بينگروهى و تعامل

\begin{tabular}{|c|c|c|c|c|c|c|c|}
\hline ضريب اتا & سطح معنادارى & درجه آزادى خطا & درجه آزادى فرض & $\mathrm{F}$ & مقدار & منبع تغييرات & متغير \\
\hline 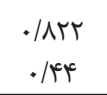 & $\begin{array}{l}.1 \cdot 1 \\
.1 \cdots 1\end{array}$ & $\begin{array}{l}T V \\
T V\end{array}$ & $\begin{array}{r}r \\
r\end{array}$ & $\begin{array}{l}\text { س } \\
1 . / 4 .\end{array}$ & . /AT & آزمون × عضويت گروهيى & امنيت روانى \\
\hline $\begin{array}{l}. / 419 \\
. / V \& S\end{array}$ & $\begin{array}{l}.1 . r \Delta \\
. \% 1\end{array}$ & $\begin{array}{l}\text { TV } \\
\text { TV }\end{array}$ & $\begin{array}{l}r \\
r\end{array}$ & $\begin{array}{l}r / v \wedge \\
r q / \Delta q\end{array}$ & $\begin{array}{l}. / 4 T \\
. / M E\end{array}$ & آزمون × عضويت گرووهى & اضطراب \\
\hline
\end{tabular}

همجِنين بر اساس نتايج اين جدول، عامل آزمون براى

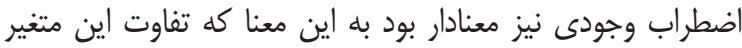

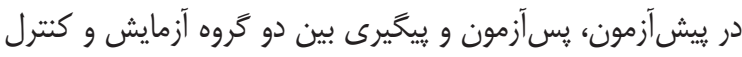

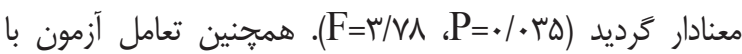
عضويت كروهى نيز معنادار شد و اين بدان معناست كه اضطراب وجودى بر حسب عضويت گروهى (كروه آزمايش و كنترل) در سه

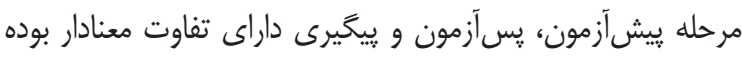
است (1)
نتايج تحليل واريانس اندازهگيرى مكرر (جدولء) نشان داد

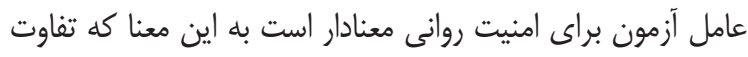

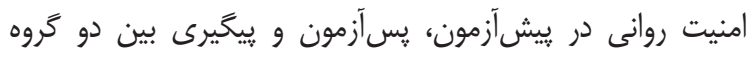

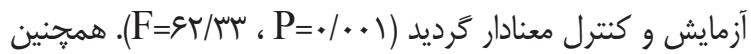
تعامل آزمون با عضويت كَروهى نيز معنادار شد و اين بدان معناست كه امنيت روانى بر حسب عضويت كروهى (گروه آزمايش و كنترل)

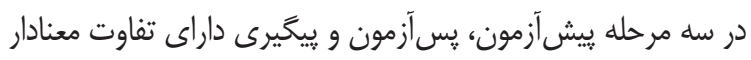

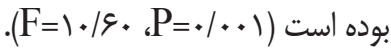

جدول ه: نتايج تحليل واريانس اندازمَيرى مكرر براى عامل درون كروهى و تعامل عامل درون كروهى و بين كروهى

\begin{tabular}{|c|c|c|c|c|c|c|c|}
\hline Eta & Sig & $\mathrm{F}$ & MS & $\mathrm{df}$ & SS & منبع تغييرات & متغير \\
\hline $\begin{array}{l}. / V I S \\
. / M T E\end{array}$ & $.1 \cdot .1$ & 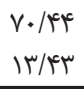 & $\begin{array}{l}\text { DIT/DF } \\
Q Y / V F\end{array}$ & $\begin{aligned} r \\
r\end{aligned}$ & $\begin{array}{l}1 \cdot r \Delta / \cdot \Lambda \\
19 \Delta / 4 \Lambda\end{array}$ & آزمون × عضويت كَروهى & امنيت روانى \\
\hline $\begin{array}{l}. / 114 \\
.199 \\
\end{array}$ & $\begin{array}{l}.1 .14 \\
.1 .01 \\
\end{array}$ & $\begin{array}{l}9 / T E \\
\Delta F / T H\end{array}$ & $\begin{array}{l}|0 I / V| \\
\mid M T / N V \\
\end{array}$ & $\begin{array}{l}1 / \% \Lambda \\
1 / 4 \Lambda\end{array}$ & $\begin{array}{l}190 / 4 \lambda \\
1891 / 14\end{array}$ & آزمون × عضويت گروهي & اضطراب \\
\hline
\end{tabular}

يبيخيرى) با كروه (كروههاى آزمايش و كنترل) معنادار بود و اين بدان

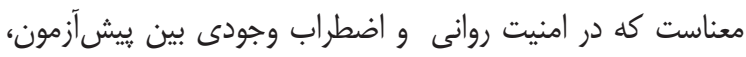

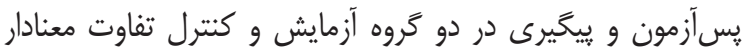

نتايج ديخر نشان داد بين ييشآزمون، يسآزمون و يِيخيرى

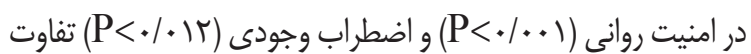

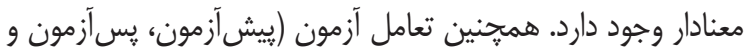




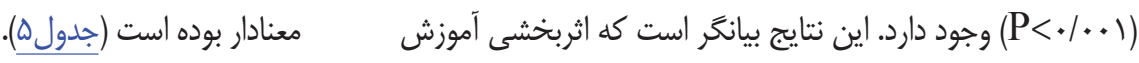

$$
\begin{aligned}
& \text { هستى شناسى بر امنيت روانى و اضطراب وجودى در سالمندان }
\end{aligned}
$$

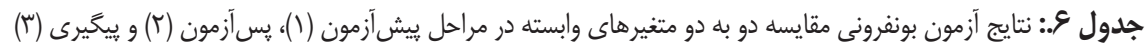

\begin{tabular}{|c|c|c|c|c|c|c|c|}
\hline \multicolumn{2}{|c|}{ فاصله اطمينان ه9\%٪ } & \multirow{2}{*}{ سطح معنادارى } & \multirow{2}{*}{ خطاى استاندارد } & \multirow{2}{*}{ تفاوت ميانگين } & \multirow{2}{*}{\multicolumn{2}{|c|}{ مرحله }} & \multirow{2}{*}{ متغير } \\
\hline حد بالا & حد يايين & & & & & & \\
\hline$-\omega / \cdot \Delta$ & $-\Lambda / Y \Lambda$ & $.1 \cdot \cdot 1$ & | س & $-q / 9 V$ & $(r)$ & & \\
\hline$-\Delta / \Delta V$ & $-q / \Delta q$ & $.1 \cdot+1$ & $\cdot / \mathrm{VA}$ & $-V / \Delta S$ & $(\mu)$ & (1) & \\
\hline$\Lambda / T \Lambda$ & $\Delta / \cdot \Delta$ & $.1 \cdot+1$ & س & $\varepsilon / 9 V$ & (1) & & \\
\hline$\cdot / \mathrm{V} \wedge$ & $-r / \Delta \Lambda$ & $\cdot / \Delta \Delta F$ & .198 &.$- / 9$. & $(\Psi)$ & (1) & امنيت رواسى \\
\hline $9 / \Delta S$ & $\Delta / \Delta V$ & $.1 \cdot+1$ & $\cdot / \mathrm{V} \Lambda$ & $V / \Delta S$ & (1) & (س) & \\
\hline$r / \Delta \Lambda$ & $-\cdot / v \Lambda$ & $\cdot \mid \Delta \Delta F$ & .198 &.$/ 9$. & $(T)$ & (1) & \\
\hline$r / V^{c}$ &.$-|9|$ & 政 & •/AD & $1 / \Delta F$ & $(r)$ & & \\
\hline$V / \cdot r$ &.$/ I V$ & ( & $1 / r F$ & $r / \varepsilon$. & (ए) & (1) & \\
\hline$\left.\cdot|9|\right|^{4}$ & $-r / N{ }^{*}$ & • & $\cdot / \Lambda \Delta$ & $-1 / \Delta S$ & (1) & & \\
\hline$r / 9 \Lambda$ & $\cdot 1 \cdot 1 \mathrm{~V}$ & טץ./. & $\cdot / V q$ & $r / \cdot r$ & $(\mu)$ & (1) & اصطراب و \\
\hline.$- / 199$ & $-V / \cdot r$ & • & $1 / \mu r$ & $-r / \varphi$. & (1) & & \\
\hline$-\cdot / \cdot \wedge \mathrm{V}$ & $-r / 9 \Lambda$ & ט ג & ./VG & L & $(r)$ & (T) & \\
\hline
\end{tabular}

تفاوت در اضظراب وجودى بين دو مرحله يِيشآزمون و پِآزمون

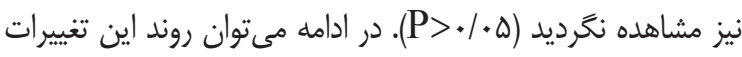
را به صورت نمودارهاى تفاوت ميانكَين دو كروه آزمايش و كنترل

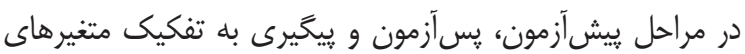

وابسته (امنيت روانى و اضطراب وجودى) مشاهده نمود (شكل ().).

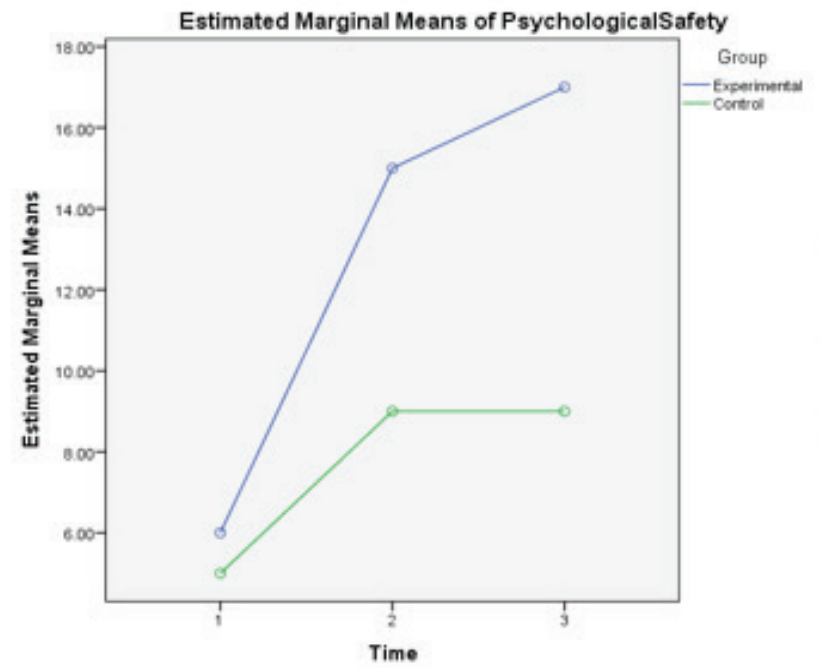

نتايج مقايسه دو به دو (آزمون بونفرونى) بر اساس سه

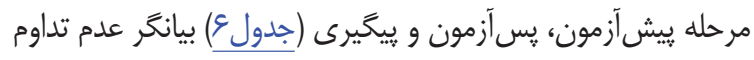
اثربخشى معنادار آموزش هستى شناسى بر امنيت روانى سالمندان

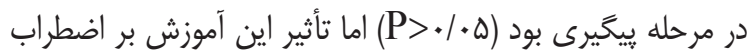

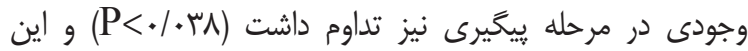

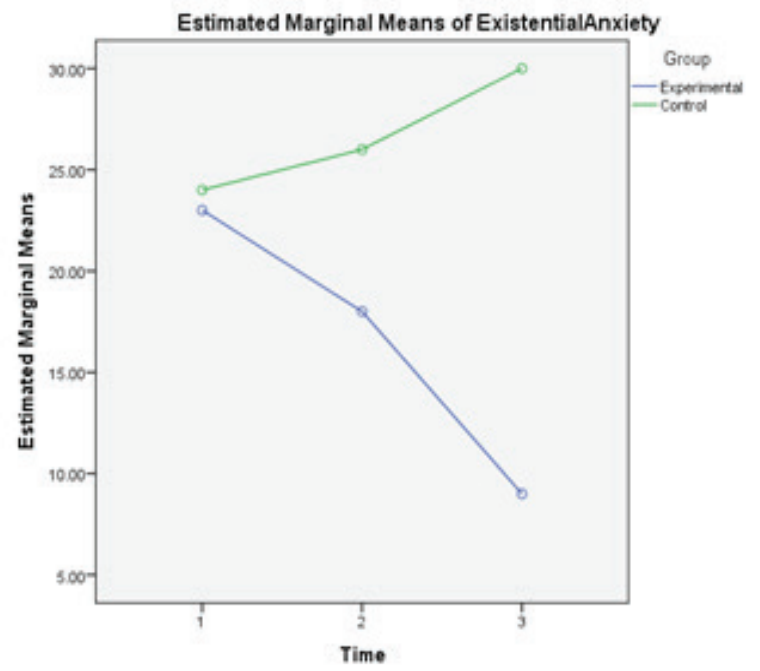

شكل (: روند تغييرات ميانكين دو كروه آزمايش و كتترل در مراحل ييش آزمون، يسآزمون و يبيكيرى به تفكيك متغيرهاى وابسته (امنيت روانى و اضطراب وجودى)

آن مانند هدفمندى، اعتماد بين فردى، امنيت روانى، انزواى وجودى، معنويت، تابآورى و ... بر احساس امنيت ذهنى و روانى تأثير معنادار

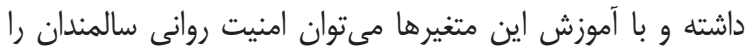

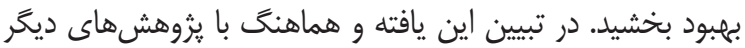

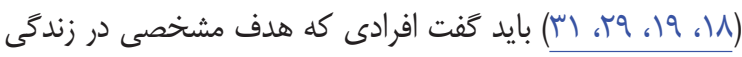
يروهش حاضر با هدف بررسى اثربخشى آموزش امنيت هستىشناختى بر امنيت روانى و اضطراب وجودى سالمندان انجام گرديد. نتايج تحليل واريانس اندازمَّيرى مكرر نشان داد آموزش امنيت هستى شناختى مبتنى بر نظريه گيدنز و متغيرهاى مرتبط با 
با بررسى نقش مفاهيم هستىشناختى مانند اعتماد، خودكارآمدى، اميدوارى، مسئوليتيذيرى اجتماعى، همدلى و هدفمندى در احساس امنيت درونى، هويتيابى، ترس از مرگ و عدم بيشانگى از خويشتن

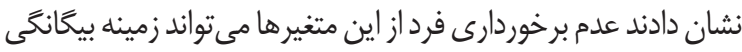
فرد از خويشتن را ايجاد نموده، امنيت روانى و اجتماعى را مختل و فرد را جهت مقابله با مشكلات روزمره ناتوان نمايد. بريتبارت (Iاس) نيز برخى نحَرانى هاى مرتبط با هستىشناختى را شامل فقدان آزادى، احساس انزوا و تنهايى فردى و اجتماعى، عدم مسئوليتيذيرى و عدم

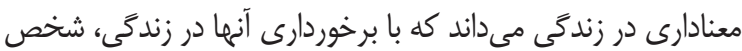
مىتواند آرامش و امنيت بيشترى داشته، رضايتش از زندكى افزايش

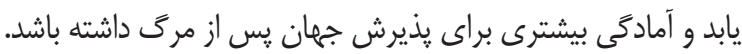

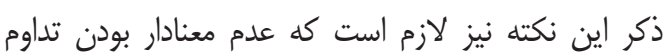
اثربخشى آموزش هستىشناختى بر امنيت روانى در مرحله يِيخيرى و

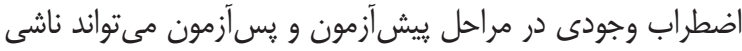

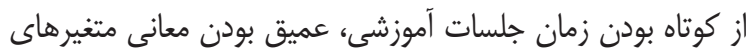
هستى شناختى و نيازمندى بيشتر جهت درك دقيق اين مفاهيه است

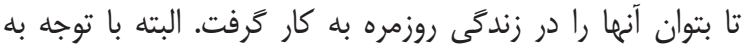
مشكلات جسمانى سالمندان و خستخى مفرط آنها، يُوهشگَران مجبور بودند زمان جلسات را هر خه كمتر انتخاب نمايند. بنابراين به يزوهشًَران بعدى توصيه مى گردد به اين مورد توجه كافى نمايند. در يايان بايد اشاره نمود مهمترين محدوديت اين يزوهش نيز جنسيت بود كه با توجه به محدود بودن تعداد مردان سالمند در مراكز مراقبت

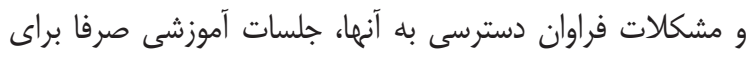
زنان اجرا گرديد. بنابراين امكان تعميم نتايج اين مطالعه به مردان سالمند وجود ندارد. بر اين اساس، يِيشنهاد مى گردد يُروهش حاضر بين مردان نيز انجام گيرد و نتايج مربوط به زنان و مردان با هم مقايسه گردد.

\section{نتيحه كيرى نهايدي}

آموزش متغيرهاى مرتبط با امنيت هستىشناختى مىتواند

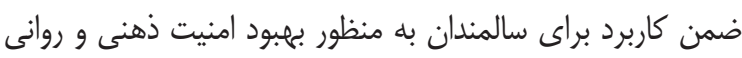
آنها، باعث كاهش ميزان اضطراب وجودى شده و بخشى از فشارهاى

$$
\text { روزمره آنها را كاهش دهد. }
$$

\section{References}

1. Attari B, Monirpour N, Zargham Hejabi M. The relationship of happiness with selfacceptance, appreciation and forgiveness
دارند، به طور منطقى به ديخران اعتماد نموده و روابط اجتماعى مناسبى برقرار مى كنند، از قابليتهاى معنوى مانند صداقت، ايمان به قدرت برتر و زندگى يس از مرگ، اخلاق و ... برخوردارند و در برابر مشكلات روزمره تحمل كافى دارند سيرى را در برابر خويش ايجاد مى كنند كه از آنها در برابر استرسها و فهمل فهارهاى متعدد محافظت كرده و امنيت و آرامش درونى را براى آنان به ارمغان مىآورد. بديهى است اين امنيت ذهنى و روانى به فرد امكان مى دهد عملكرد مطلوبى بـ در زندكى فردى، خانوادگى و اجتماعى خويش داشته (Tr) و همراه با ييشرفت و نوآورى در انواع فعاليتها، ديدگًاه بهترى نيز درباره آينده خويش داشته باشد كه ييامد آن، افزايش احساس امنيت در محيط

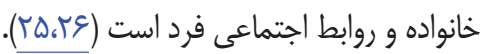
همجنين تحليل واريانس اندازهيرى مكرر در يثوهش حاضر بيانكر معنادار بودن اثربخشى آموزش امنيت هستىشناختى مبتنى بر نظريه گيدنز و متغيرهاى مرتبط با آن بر اضطراب وجودى سالمندان

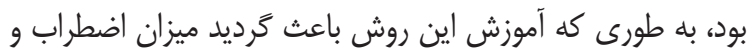
نحرانى ناشى از مفاهيم وجودى مانند مرگ، احساس تنهايى و انزوا، ترس از آينده و ... در سالمندان كاهش يافته و زمينه بهبود روابط فردى و اجتماعى آنان نيز فراهم گَردد. آنجهه در تبيين اين يافته و

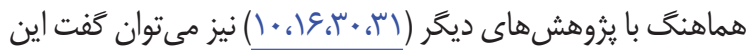
است كه نخَرانىهاى مرتبط با رويكرد هستىشناسى مانند استقلال فردى، اميد به آينده، معناى زندگى، هدفمندى، اراده آزاد، انتخاب شخصى و معنويت در زندگى فردى و اجتماعى افراد گروههماى سنى مختلف به ويثه سالمندان اهميت فراوانى داشته و برخوردارى از معنا و هدف مشخص در زندگى مىتواند باعث گَردد فرد اهداف روشنى را در زندگى خويش تعيين كرده، امنيت روانى داشته باشد و با آرامش بيشترى خود را براى زندگى يس از مرگ آماده نمايد (وَ،ی). بديهى

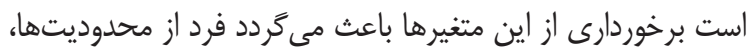

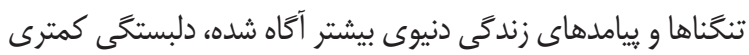

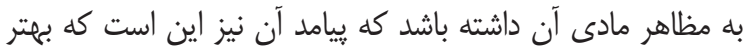

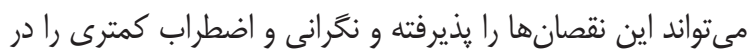
آخرين مرحله زندكى خويش (سالمندى) تجربه نمايد و زمينه يذيرش

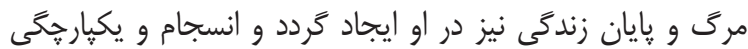
بيشترى داشته باشد. گَيدنز و ساتون (عا) نيز هماهنَ با نتايج يخوهش حاضر،

in the elderly: the role of mediating selfempowerment, Journal of Aging Psychology, 2019; 4 (3): 197-211.

2. Statistical Center of Iran. The goals of 
census. I.R. Iran. 2019. https://www.amar. org.ir

3. World Health Organization: World population ageing. Geneva: world health Organization. 2019.

4. Boloursaz Mashhadi H. The relationship between emotional intelligence and psychological well-being and self-efficacy in elderly women in Karaj. Journal of Organizational Behavioral Management in Sport Studies, 2018; 4 (2), 41-51.

5. Mostafaei A, Ghaderi D. The Relationship between Emotional Intelligence and Psychological Capital with Elderly Life Satisfaction. Journal of Gerontology, 2019; 3 (3): 51 - 58.

6. Bousquet J, Malva J, Nogues M, Mañas LR, Vellas B, Farrell J, et al. Operational definition of active and healthy aging (AHA): The European innovation partnership (EIP) on AHA reference site questionnaire: Montpellier October 20-21, 2014, Lisbon July 2, 2015. Journal of the American Medical Directors Association. 2015; 16(12), 1020 - 1026.

7. Naseh L, Sheikhi RA, Rafiei H. General self-efficacy and its related factors in the elderly living in the elderly. Journal of Holistic Nursing and Midwifery, 2016; 26 (80): 90-97.

8. Etemad J, Dehghan Menshadi Z, Mozafari N. Psychometric Properties of Existential Anxiety Scale in the Elderly. Journal of Gerontology, 2016; 1(3): 39 - 48.

9. Su H, Cao J, Zhou Y, Wang L, Xiang L. The mediating effect of coping style on personality and mental health among elderly Chinese empty-nester: A cross-sectional. Archives of Gerontology and Geriatrics, Archives of Gerontology and Geriatrics. 2018; 75, 197 - 201.

10. Shaver PR, Mikulincer M. Meaning, Mortality, and Choice: The Social Psychology of Existential Concerns. American Psychological Association Press, 2012.

11. Udo C, Melin-Johansson $\mathrm{CH}$, Danielson E. Existential Issues Among Health Care Staff in Surgical Cancer Care Discussions in
Supervision Sessions. European Journal of Oncology Nursing, 2011; 15, 447-453.

12. Nazari ZM, Zarghami S. Existential Psychotherapy: Individual and Group Therapy. Tehran: Pazineh Publishing, 2009.

13. Corsini RJ. Handbook of Innovative Therapies. Journal of Palliative Medicine, 2008; 9 (6), 1376-1387.

14. Giddens A. Modernity and Self-identity: Self and Society in the Late Modern Age. Stanford University Press, 2002.

15. Hosseini Beheshti M, Ezheie F. Design and implementation of the ontology of basic sciences based on the concepts and relationships in related thesauri. Journal of Processing and Managing Information, 2015; 30 (3), 677-696.

16. Giddens A, Sutton PW. Sociology. London: Polity Press, 2014.

17. Maktoubian M, Dezfulian A. An overview of the ideas of the last modernist sociologist Antony Giddens. Third National Conference on Sociology and Social Sciences, 2015.

18. Montazerol Hojja M, Sharifnejad M, Rajabi M. Measurement of physical factors affecting the sense of security in urban spaces from the viewpoint of the elderly (Case study: Khan Square, Yazd). Journal of Iranian Architecture and Urban Development, 2019; 9 (15), 91-105.

19. Isa Loo $\mathrm{SH}$, Jom'ehpour $\mathrm{M}$, Khaksari Rafsanjani A. The needs and problems of the elderly in urban space. Journal of Social Work Research, 2015; 2 (6), 1-41.

20. Neyazi M, Shadfar Y. The relationship between the level of social trust and the sense of social security among women in the north (1 and 2) and southern regions (19 and 20) in Tehran. Journal of Urban Studies, 2011; 1 (1), 16-21.

21. Hamidipoor R, Rajabi F. Predicting the sense of social security based on social identity, cultural intelligence and spirituality. Journal of Strategic Research on Security and Social Order, 2018; 7 (1): 97-111.

22. Shams Morkani GH, Mokhtari S, Zrmandaee M. Investigating the relationship between silence, psychological security and employee silence. Quarterly Journal of New 
Thoughts of Education, 13 (2), 7-24.

23. Hirak R, Chunyan PA, Carmeli A, Schaubroeck JM. Linking leader inclusiveness to work unit performance: the importance of psychological safety and learning from failures. Journal of Elsevier. 2012; 23, 107-117.

24. Edmondson A. Psychological safety and learning behavior in work teams. Journal of Administrative Science Quarterly. 1999; 44, 350-383.

25. Gong Y, Wang M, Haung JC. Unfolding the proactive process for creativity: Integration of the employee proactivity, information exchange and psychological safety prospective. Journal of Management. 2012; 38 (5), 1611-1633.

26. Higgins M, Ishimura A, Holcombe R, Fowler A. Examining organizational learning in schools: The role of psychological safety, experimentation and leadership that reinforces learning. Journal of Spring. 2012; 13, 67-94.

27. Weems CF, Costa NM, Dehon CH, Berman SL. Paul Tillich's theory of existential anxiety: A preliminary conceptual and empirical examination. Anxiety, Stress \& Coping: An International Journal. 2004; 4, 383-399.

28. Van Deurzen E. Existential counseling and psychotherapy in practice. londan: SAGE publication, 2002.

29. Hajiazizi AH, Bahmani B, Mahdi N, Manzari Tavakoli V, Barshan A. Effectiveness of Group Logo therapy on Death Anxiety and Life Expectancy of the Elderly Living in Boarding Houses in Kerman. SAJA. 2017; 12 (2), 220-231.

30. Mostafapour V, Motamedi A, Farrokhi H. The Effectiveness of Group Therapy on SelfEsteem and Death Anxiety in Older Women. Journal of Women and Culture, 2019; 9 (36), 23-36.

31. Breitbart W. Existential isolation. Journal of Palliate Support Care. 2017; 15 (4), 403 404.

32. Delavar A. Research Methods in Psychology and Educational Sciences. Tehran: Virayesh Publishing, 2018.
33. Karandish M, Mahdad A, Golparvar M. Developing an ontology curriculum based on Giddens theory and determining its effectiveness on job alienation, job burnout, marital satisfaction, role conflict and role ambiguity in prison staff in Kohgiluyeh and Boyer Ahmad. Ph.D. in Psychology, Islamic Azad University, Isfahan Branch (Khorasgan).

34. Hosseinpour D, Ermandi M, Valdi R. The Impact of Psychological Capital on Knowledge Sharing with the Intermediary of Psychological Security: Case; Sharif University of Technology. Research and Planning in Higher Education, 2016; 22 (4), 133-154.

35. Ghanbari S, Zandi KH, Dehghan, A. Analysis of genuine leadership relations, psychological security and organizational citizenship behavior. Journal of State Administration Mission, 2016; 7 (22): 3545.

36. Tillich P. The Courage to Be. New Haven, CT: Yale University Press, 1952. 